\title{
Isolation and detection of Corynebacterium pseudotuberculosis in the reproductive organs and associated lymph nodes of non-pregnant does experimentally inoculated through intradermal route in chronic form
}

\author{
Nur Amirah Abdul Latif ${ }^{1}$, Faez Firdaus Jesse Abdullah ${ }^{1,2}$, Aishatu Mohammed Othman ${ }^{1}$, Adza Rina ${ }^{3}$, Eric Lim Teik Chung ${ }^{1}$ \\ Mohd Zamri-Saad ${ }^{3}$, Abdul Aziz Saharee ${ }^{1}$, Abdul Wahid Haron ${ }^{1,2}$ and Mohd Azmi Mohd Lila ${ }^{3}$ \\ 1. Department of Veterinary Clinical Studies, Faculty of Veterinary Medicine, Universiti Putra Malaysia, 43400 Serdang, \\ Selangor, Malaysia; 2. Research Centre for Ruminant Disease, Universiti Putra Malaysia, 43400 Serdang, Selangor \\ Malaysia; 3. Department of Veterinary Pathology and Microbiology, Faculty of Veterinary Medicine, Universiti Putra \\ Malaysia, 43400 Serdang, Selangor, Malaysia. \\ Corresponding author: Faez Firdaus Jesse Abdullah, e-mail: jesseariasamy@gmail.com, \\ NAAL: nuramiraha.I@gmail.com, AMO: aishatuothman@yahoo.co.uk, AR: adza_rina@yahoo.com, \\ ELTC: eric88lim@gmail.com, MZS: mzamri@upm.edu.my, AAS: abdaziz@upm.edu.my, AWH: wahidh@upm.edu.my, \\ MAML: azmi@upm.edu.my \\ Received: 03-02-2015, Revised: 22-06-2015, Accepted: 30-06-2015, Published online: 29-07-2015
}

doi: 10.14202/vetworld.2015.924-927 How to cite this article: Latif NAA, Abdullah FFJ, Othman AM, Rina A, Chung ELT, Zamri-Saad M, Saharee AA, Haron AW, Lila MAM (2015) Isolation and detection of Corynebacterium pseudotuberculosis in the reproductive organs and associated lymph nodes of non-pregnant does experimentally inoculated through intradermal route in chronic form, Veterinary World 8(7):924-927.

\begin{abstract}
Aim: Corynebacterium pseudotuberculosis is the etiological agent of caseous lymphadenitis that affects sheep and goats. This study was designed to determine the presence of the causative organism in the female reproductive organs and associated lymph nodes in non-pregnant does experimentally inoculated through intradermal route in the chronic form.

Materials and Methods:18 non-pregnant healthy Katjang does aged 2-year-old were divided randomly into two groups. The first and second group consists of nine non-pregnant does each and the two groups were subdivided into three subgroups. The first group was experimentally inoculated with $1 \mathrm{ml}$ of $10^{7} \mathrm{cfu}$ of live C. pseudotuberculosis through intradermal route, whereas the second group was inoculated with $1 \mathrm{ml}$ phosphate buffer saline $(\mathrm{pH} 7)$ solution intradermally. The first group were further subdivided into three subgroups where, the first subgroup (B1) were kept for 30 days post-infection, second subgroup (B2) were kept for 60 days post-infection, and third subgroup (B3) were kept for 90 days. The second group was further subdivided into three subgroups $(\mathrm{C} 1, \mathrm{C} 2$, and $\mathrm{C} 3$ ) where they were kept for 39, 60, and 90 days post-infection, respectively.

Results: From this study, there was successful isolation of $C$. pseudotuberculosis from the reproductive organs of the treatment group after 60 days post-infection. The subgroups (B1, C1, C2, and C3) did not show any presence of the causative organism in the reproductive organs. The second subgroup B2 and third subgroup B3 showed positive isolation of the causative organisms from the ovary, uterine horns, uterus, cervix, vagina, and inguinal lymph node of the experimental non-pregnant does.
\end{abstract}

Conclusion: This study showed that chronic infection of C. pseudotuberculosis via intradermal route may cause effect toward the reproductive organs and may be able to influence the reproductive efficiency of the infected animals.

Keywords: Corynebacterium pseudotuberculosis, chronic form, reproductive organs, lymph nodes, detection.

\section{Introduction}

Caseous lymphadenitis (CLA) of goats, caused by Corynebacterium pseudotuberculosis, has been a significant disease in the majority of goats-rearing regions for over a century. This cheesy gland disease can potentially threaten the Malaysian livestock industry, where the economic loss is significant [1]. This is mainly due to the reduction of wool, meat, and milk production, decrease reproductive efficiencies of affected animals and condemnation of carcasses and skins in abattoirs [2,3].

C. pseudotuberculosis organism is a facultative, Gram-positive, and intracellular coccobacillus consisting of two biotypes: A nitrate positive group

Copyright: The authors. This article is an open access article licensed under the terms of the Creative Commons Attributin License (http:// creative commons.org/licenses/by/2.0) which permits unrestricted use, distribution and reproduction in any medium, provided the work is properly cited. infecting only horses and nitratenegative group infecting only goats and sheep [4]. The C. pseudotuberculosis infection occurs after it penetrates into the skin or mucous membranes of susceptible hosts. Most infection of $C$. pseudotuberculosis occurs through a direct contact with purulent exudates that came from rupturing of external and pulmonary abscesses [5]. Skin abrasions due to ear tagging, castration, shearing, docking, and by environmental hazards such as nails, wired fences, splintered wood, and metal edges are the possible indicator for CLA transmission within a herd [6]. C. pseudotuberculosis lacks of a tendency to multiply in the environment. However, the bacteria, C. pseudotuberculosis can survive for 2-8 months, or more in the environment and any skin abrasions help in persistence transmission of this disease [5].

According to Dercksen et al. [7] CLA is an economically important zoonotic disease of small 
ruminants worldwide and is characterized by the formation of abscess in the peripheral lymph nodes and in the lungs. Dorella et al. [5] explained in detailed that the most frequent form of the disease is characterized by the formation of abscess superficially in lymph nodes and in subcutaneous tissues. Dorella et al. [5] also added that these abscesses can also develop internally in organs such as in lungs, liver, kidneys, and spleen, characterizing visceral CLA. Taking into an account, due to lack of information on CLA infection in the reproductive organ of goats, their associated lymph node and its relation with the pituitary gland, this study was conducted.

Clinical identification of C. pseudotuberculosis in CLA affected goats using serodiagnostic tests are either lack of specificity or sensitivity [8]. Despite that, enzyme-linked-immunosorbent assay (ELISA) seems to be effective in controlling and eradicates CLA disease in affected herds [7]. However, some of ELISA tests are influence by vaccination in animal [9]. Furthermore, it costs a lot of money to run an ELISA tests for more than 96 samples. Hence, ELISA test cannot give a promising results and it is quite expensive to use by the farmers but reasonable to be use in research area [10]. Other than that, other promising diagnostic test would be polymerase chain reaction (PCR) that are widely use in research area and in livestock farm that in need for identification of C. pseudotuberculosis in clinical samples [11]. PCR is not involving a lot of steps to get the promising results. Hence, PCR always be the suggested method in detecting CLA in disease animals [5].

Khuderet al. [12] stated that C. pseudotuberculosis and its exotoxin (phospholipase D) able to cause disruption in reproductive hormones in mice model. There is a paucity of information in isolation of this organism from the reproductive tract of female goats in chronic infection. PCR has become one of the diagnostic tool in isolation and identification of C. pseudotuberculosis where this method owing to its advantage of specificity and sensitivity [13]. Therefore, this study was designed to determine the presence of the causative organism in the female reproductive organs and associated lymph nodes in non-pregnant does experimentally challenged with C. pseudotuberculosisintradermally for chronic form.

\section{Materials and Methods}

\section{Ethical approval}

The experimental procedure was conducted under the approval of the Animal Care and Use Ethics Committee reference number (UPM/IACUC/AUPR29/2014)Universiti Putra Malaysia as required in Malaysia by the Animal Welfare Act (2014).

\section{Animals and management}

Eighteen healthy non-pregnant Katjang does aged 2 -year-old with an average weight of $30 \pm 5 \mathrm{~kg}$ were used in this study. The non-pregnant does were acclimatized for 2 weeks prior to the experiment and were fed with commercial goat pellets $(300 \mathrm{~g} /$ goats/day) and cut Napier grass. Swab samples from the nasal, vagina and oral mucosa, and blood via jugular venipuncture were collected for screening of C. pseudotuberculosisprior to the experiment. The non-pregnant does were randomly divided into two groups (Group 1 and Group 2) of nine non-pregnant does each group. The first group were further subdivided into three subgroups where the first subgroup (B1) were kept for 30 days post-infection, second subgroup (B2) were kept for 60 days post-infection and third subgroup (B3) were kept for 90 days post-infection. The second group was also further subdivided into three subgroups $(\mathrm{C} 1, \mathrm{C} 2$, and $\mathrm{C} 3)$ where the non-pregnant does were kept for 30, 60 and 90 days post-infection respectively. The first group was experimentally inoculated with $1 \mathrm{ml}$ of $10^{7} \mathrm{cfu} / \mathrm{ml}$ live C. pseudotuberculosis whereas the second group was inoculated with $1 \mathrm{ml}$ of phosphate buffer saline (PBS) $\mathrm{pH}$ (7) via intradermal route at the neck region.

\section{c. pseudotuberculosis inoculum preparation}

C. pseudotuberculosis colony that was previously isolated from an outbreak of clinical caseous lymphadenitis cases among goats at Universiti Putra Malaysia was used in this study. The organism were isolated and subcultured onto newly prepared blood agar media and incubated at $37^{\circ} \mathrm{C}$ for $48 \mathrm{~h}$. Twenty colonies were inoculated into $500 \mathrm{~mL}$ of brain heart infusion broth and incubated at $37^{\circ} \mathrm{C}$ for $48 \mathrm{~h}$. The Alcamo Plate count method was used to determine the bacteria concentration where $10^{7} \mathrm{cfu} / \mathrm{ml}$ was used in this study.

\section{Does and inoculation}

Twelve non-pregnant Katjang does were divided randomly into two equal groups. The group (1) was inoculated with $10^{7}$ colony forming unit/1 $\mathrm{ml}$ of live C. pseudotuberculosis through intradermal route at the neck region and the second group (2) was given $1 \mathrm{ml}$ of PBS intradermal and serves as the control. Following infection, the animals were observed daily for clinical signs for 90 days.

\section{Sampling and culture}

For three consecutive months of post-treatment, blood samples were collected periodically and subjected for further analysis. The non-pregnant does were slaughtered at 30,60 , and 90 days post-infection and the reproductive organs (ovary, uterus, uterine horn, cervix, and vagina) and inguinal lymph nodes were collected. Swab samples were taken all these organs and were cultured in blood agar at $37^{\circ} \mathrm{C}$ for $48 \mathrm{~h}$. Any suspected growth of C. pseudotuberculosis was subjected to PCR analyses.

\section{PCR condition}

The PCR was performed in SensQThermocycler machine and was set with 30 cycles of amplification, following an initial denaturating step at $94^{\circ} \mathrm{C}$ for 5 min. Each cycle involved denaturation at $94^{\circ} \mathrm{C}$ for 
$1 \mathrm{~min}$, annealing at $56^{\circ} \mathrm{C}$ for $1 \mathrm{~min}$, synthesis at $72^{\circ} \mathrm{C}$ for $2 \mathrm{~min}$, and final synthesis at $72^{\circ} \mathrm{C}$ for $2 \mathrm{~min}$. For each PCR tube, a total of $50 \mu 1$ reaction volume containing $2 \mu 1$ DNAzol as template DNA, $2 \mu 1$ of $25 \mathrm{Mm}$ $\mathrm{MgCl}_{2}, 2 \mu \mathrm{l}$ of $\times 10$ Taq buffer with $\left(\mathrm{NH}_{4}\right)_{2} \mathrm{SO}_{4}, 0.5 \mu \mathrm{l}$ of $10 \mathrm{mMdNTP}$ mix, $0.5 \mu \mathrm{l}$ forward primer, $0.5 \mu \mathrm{l}$ reverse primer, $0.5 \mu \mathrm{l}$ Taq DNA polymerase $(5 \mathrm{u} / \mu \mathrm{l})$, and $42 \mu \mathrm{l}$ sterile distilled water were added respectively. The amplified products were analyzed by electrophoresis on a $1 \%(\mathrm{w} / \mathrm{v})$ agarose gel with the addition of $1.5 \mu 1$ FloroSafe DNA stain and run at 60 volts $(\mathrm{V})$, 350 milliAmpere $(\mathrm{mA})$ for $68 \mathrm{~min}$.

\section{Primer design}

The oligonucleotide primer used in this study was 16S rRNA gene [11]. The forward primer used was (5'CCGCACTTTAGTGTGTGTG'3) and the reversed primer was (5'TCTCTACGCCGATCTTGTAT'3) respectively. The PCR products were detected as C. pseudotuberculosis according to the molecular size of $816 \mathrm{bp}$ as documented [11].

\section{Results}

Group 2 (C1, C2, and C3) and Group 1 (B1) showed negative detection of C. pseudotuberculosis from all reproductive organs (ovary, uterus, uterine horn, cervix, and vagina) and inguinal lymph node after 30 days post-infection. All non-pregnant does from group B3 showed positive results of detection C. pseudotuberculosis from all reproductive organs and inguinal lymph node after 90 days post-infection. For Group B2 only two out of three non-pregnant does showed positive detection of C. pseutoberculosis from reproductive organs whereas for inguinal lymph node all three non-pregnant does were positive with the causative organism after 60 days post-infection. The results are summarized in Tables- 1 and 2 .

\section{Discussion}

C. pseudotuberculosis is the causative agent of CLA in ruminants $[12,13]$. Although the bacterium causes low mortality, but it may influences the fertility of the infected animal, which may lead to major economic losses [14]. Infertility is one of the major problem dealt by goat industry where anything interferences with the reproductive system will lead to an infertile animal [15]. Bacterial infection is one of the causes for reproductive failure in ruminants [16]. Othman et al. [17] have reported that does infected with $C$. pseudotuberculosis for a period of 30 days able to cause disruption in the reproductive hormones where the change of the hormones resembles pseudopregnancy in a doe. To date, there is a paucity of information related to chronic infection of C. pseudotuberculosis in does related to reproductive organs. The results of this study added knowledge to this field. From this study all the treatment groups showed presence of causative organism in the inguinal lymph nodes after 30 days post-infection until 90 days post-infection and this result is in agreement with Dorella et al. [5], who stated the bacteria disseminates freely in the lymphatic system. The presence of this organism in the reproductive organs of the infected does after 60 and 90 days post-infection may cause infertility and presence of the bacterium in the reproductive organs may alter the secretion of female reproductive hormone $[13,14]$.

The result of this study for 30 days post-infection is not in agreement with Othman et al. [17] stated that the researcher believed presence of the causative organism in the reproductive organs may cause the changes in the reproductive hormone profiles in their study. The present study, report for the $1^{\text {st }}$ time, the presence of the causative agent in the reproductive organs and inguinal lymph nodes after 60 and 90 days post-infection with $C$. pseudotuberculosis via the intradermal route. The findings from this study differ from a study conducted by Valli and Perry [18] stated reproductive organs are the least frequently affected organs during CLA infection. Hence, this study indicates possible transmission of $C$. pseudotuberculosis in reproductive organs and associated lymph nodes during prolong infection that may cause a reproductive failure that can contribute to the economic loss.

\section{Conclusion}

In conclusion, this study revealed the presence of the causative organism in the reproductive organs and associated lymph nodes of non-pregnant does inoculated via intradermally in the chronic form. These findings may explain the infertility among does infected with CLA for a long period of time.

\section{Authors' Contributions}

FFJA, MZS, AAS, AWH, and MAML conceptualized and supervised the research. NAAL, AMO, AR, and ELTC collected samples, drafted the manuscript

Table-1: Detection of Corynebacterium pseudotuberculosis in Group 1 of non-pregnant Katjang does inoculated intradermally.

\begin{tabular}{|c|c|c|c|c|c|c|c|c|c|c|}
\hline \multirow[t]{2}{*}{ Organs } & \multirow{2}{*}{$\begin{array}{c}\text { Subgroup } \\
\text { Goat }\end{array}$} & \multicolumn{3}{|c|}{ B1 } & \multicolumn{3}{|c|}{ B2 } & \multicolumn{3}{|c|}{ B3 } \\
\hline & & G1 & G2 & G3 & G4 & G5 & G6 & G7 & G8 & G9 \\
\hline Ovary & & - & - & - & + & + & - & + & + & + \\
\hline Uterine horns & & - & - & - & + & - & - & + & + & + \\
\hline Uterus & & - & - & - & + & - & - & + & + & + \\
\hline Cervix & & - & - & - & + & - & - & + & + & + \\
\hline Vagina & & - & - & - & + & - & - & + & + & + \\
\hline Inguinal lymph node & & - & - & - & + & + & + & + & + & + \\
\hline
\end{tabular}


Table-2: Detection of Corynebacterium pseudotuberculosis in Group 02 of non-pregnant Katjang does inoculated intradermally.

\begin{tabular}{|c|c|c|c|c|c|c|c|c|c|c|}
\hline \multirow[t]{2}{*}{ Organs } & \multirow{2}{*}{$\begin{array}{c}\text { Subgroup } \\
\text { Goat }\end{array}$} & \multicolumn{3}{|c|}{ C1 } & \multicolumn{3}{|c|}{$\mathbf{C 2}$} & \multicolumn{3}{|c|}{ C3 } \\
\hline & & G10 & G11 & G12 & G13 & G14 & G15 & G16 & G17 & G18 \\
\hline Ovary & & - & - & - & - & - & - & - & - & - \\
\hline Uterine horns & & - & - & - & - & - & - & - & - & - \\
\hline Uterus & & - & - & - & - & - & - & - & - & - \\
\hline Cervix & & - & - & - & - & - & - & - & - & - \\
\hline Vagina & & - & - & - & - & - & - & - & - & - \\
\hline Inguinal lymph node & & - & - & - & - & - & - & - & - & - \\
\hline
\end{tabular}

and done all statistical tests. All authors read and approved the final manuscript.

\section{Acknowledgments}

The authors would like to thank the staff of the Department of Veterinary Clinical Studies, Universiti Putra Malaysia in particular Mr. Yap Keng Chee, and Mr.GanesanmurthiPerumal. The project was funded by Ministry of Higher Education, Malaysia (Grant no: 9419000).

\section{Competing Interests} interests.

The authors declare that they have no competing

\section{References}

1. Shun, R.P.S., Faez, F.F.A., Saad, M.Z. and Haron, A.W. (2012) Clinical response and pathological changes associated with Corynebacterium pseudotuberculosis infection in mice. $7^{\text {th }}$ Proceedings of the Seminar in Veterinary Sciences. UPM Serdang, Malaysia. p46-51.

2. Paton, M.W., Collett, M.G., Pepin, M. and Bath, G.F (2005) Corynebacterium pseudotuberculosis infections. In: Coetzer, J.A.W., Tustin, R.C., editors. Infectious Diseases of Livestock. $3^{\text {rd }}$ ed. Cape Town: Oxford University Press Southern Africa. p1917-1930.

3. Arsenault, J., Girard, C., Dubreuil, P., Daignault, D., Galarneau, J.R., Boisclair, J., Simard, C. and Bélanger, D. (2003) Prevalence of and carcass condemnation from maedi-visna, paratuberculosis and caseous lymphadenitis in culled sheep from Quebac, Canada. Prev. Vet. Med., 59: 67-81.

4. Songer, J.G., Beckenbach, K., Marshall, M.M., Olson, G.B. and Kelley, L.(1988) Biochemical and genetic characterization of Corynebacterium pseudotuberculosis. Am. J. Vet. Res., 49: 223-226.

5. Dorella, F.A., Pacheco, L.G.C., Oliveira, S.C., Miyoshi, A. and Azevedo, V. (2006) Corynebacterium pseudotuberculosis: Microbiology, biochemical properties, pathogenesis and molecular studies of virulence. Vet. Res., 37: 201-218.

6. Baird, G.J. and Fontaine, M.C. (2007) Corynebacterium pseudotuberculosis and its role in ovine caseous lymphadenitis. J. Comp. Pathol., 137: 179-210.

7. Dercksen, D.P., Brinkhof, J.M.A., Dekker-Nooren, T., Maanen, K.V., Bode, C.F., Baird, G. and Kamp, E.M. (2000), A comparison of four serological tests for the diagnosis of caseous lymphadenitis in sheep and goats. Vet. Microbiol., 75: 167-175.
8. Windsor, P.A. (2011) Control of caseous lymphadenitis. Vet Clin. Food Anim. Pract., 27: 193-202.

9. Simmons, C.P., Dunstan, S.J., Tachedjian, M., Krywult, J., Hodgson, A.L. and Strugnell, R.A. (1998) Vaccine potential of attenuated mutants of Corynebacterium pseudotuberculosis in sheep. Infect. Immun., 66: 474-479.

10. Bastos, B.L., Portela, R.W.D., Dorella, F.A., Ribeiro, D., Seyffert, N., Castro, T.L.D.P., Miyoshi, A., Oliveira, S.C., Meyer, R., and Azevedo, V. (2012). Corynebacterium pseudotuberculosis: Immunological responses in animal models and zoonotic potential. J. Clin. Cell Immunol., S4: 005.

11. Çetinkaya, B., Karahan, M., Atil, E., Kalin, R., Baere, T.D. and Vaneechoutte, M. (2002) Identification of Corynebacterium pseudotuberculosis isolates from sheep and goats by PCR. Vet. Microbiol.,88: 75-83.

12. Jesse, F.F., Adamu, L., Osman, A.Y., Muhdi, A.F., Haron, A.W., Saharee, A.A., Saad, M.Z. and Omar, A.R. (2013a) Polymerase chain reaction detection of C. pseudotuberculosis in the brain of mice following oral inoculation. Int. J. Anim. Vet. Adv., 5(1): 29-33.

13. Jesse, F.F.A., Adamu, L., Hazirah, N., Osman, A.Y., Mansor, R., Haron, A.W., Saad, M.Z., Omar, A.R. and Saharee, A.A. (2013b) Clinical and reproductive pathological changes associated with Brucellamelitensis and its lipopolysaccharides in female mice via oral inoculation. Am. J. Anim. Vet. Sci., 8(3): 104-111.

14. Khuder, Z., Osman, A.Y., Jesse, F.F., Haron, A.W., Saharee, A.A., Sabri, J., Yusoff, R. and Abdullah, R. (2012) Sex hormone profiles and cellular changes of reproductive organs of mice experimentally infected with C. pseudotuberculosis and its exotoxin phospholipase D (PLD). IOSR. J. Agric. Vet. Sci., 1(3): 24-29.

15. Osmanu, S.T. (1979) Studies on bovine infertility at the agricultural research station (Legon) over half decade (1927-1977). India: Department of Animal Science Studies, Ghana University. p82.

16. Mshelia, G.D., Bilal, V.T., Maina, V.A., Okon, K., Mamza, S.A., Peter, I.D. and Egwu, G.O. (2014) Microbiological studies on genital infections in slaughtered ewes from tropical arid zone of Nigeria. Sokoto J. Vet. Sci., 12(1): $18-22$

17. Othman, A.M, Jesse, F.F.A., Adamu, L., Abba, Y., AdzaRina, M.N., Saharee, A.A., Wahid, A.H. and ZamriSaad, M. (2014) Changes in seumprogeterone and estrogen concentrations in non-pregnant boer does following experimental infection with Corynebacterium psedotuberculosis. J. Vet. Adv. 4(5): 524-528.

18. Valli, V.E.O. and Parry, B.W. (1993) Caseous lymphadenitis. In: Jubb, K.V.F., Kennedy, P.C. and Palmer, N., editors. Pathology of Domestic Animals. $4^{\text {th }}$ ed. San Diego: Academic Press. p238-240. 